\title{
The Harms That Drinkers Cause: Regional Variations Within Countries
}

\author{
Richard W. Wilsnack ${ }^{1}$, Arlinda F. Kristjanson ${ }^{1}$, Sharon C. Wilsnack ${ }^{1}$, Kim Bloomfield ${ }^{2}$, Ulrike Grittner ${ }^{3}$, Ross D. \\ Crosby 4
}

${ }^{1}$ University of North Dakota School of Medicine and Health Sciences, Grand Forks, North Dakota, USA

${ }^{2}$ Centre for Alcohol and Drug Research, Aarhus University, Copenhagen, Denmark

${ }^{3}$ Institute of Biometry and Clinical Epidemiology, Charité - Universitätsmedizin Berlin, Berlin, Germany

${ }^{4}$ The Neuropsychiatric Research Institute, Fargo, North Dakota, USA

\begin{abstract}
Aims: Multinational studies of drinking and the harms it may cause typically treat countries as homogeneous. Neglecting variation within countries may lead to inaccurate conclusions about drinking behavior, particularly regarding the harms drinking causes for people other than the drinkers. This study is the first to examine whether drinkers' self-reported harms to others from drinking vary regionally within multiple countries.

Design, Setting, and Participants: Analyses draw on survey data from 12,356 drinkers in 46 regions (governmental subunits) within 10 countries, collected as part of the GENACIS project (Wilsnack, Wilsnack, Kristjanson, Vogeltanz-Holm, \& Gmel, 2009).

Measures: Drinkers reported on eight harms they may have caused others in the past 12 months because of their drinking. The likelihood of reporting one or more of these eight harms was evaluated by multilevel modeling (respondents nested within regions nested within countries), estimating random effects of country and region, and fixed effects of gender, age, and regional prevalence of drinking.

Findings: Reports of causing one or more drinking-related harms to others differed significantly by gender and age, and also differed significantly by regions within countries. Reports did not differ significantly by regional prevalence of drinking.

Conclusions: National and multinational evaluations of adverse effects of drinking on persons other than the drinkers should give more attention to how those effects may vary regionally within countries.
\end{abstract}

In recent years, multinational research on alcohol consumption and its consequences has become common, with one major limitation. Countries are usually treated as homogeneous units, with no attention to variations within countries. This may seem justified if (a) research is based on only one or two sites in each country (Borges et al., 2010); (b) alcohol consumption is not prevalent enough for regional analyses (Clausen, Rossow, Naidoo, \& Kowal, 2009); (c) other key variables may not occur often enough for regional analyses (Bloomfield, Wicki, Wilsnack, Hughes, \& Gmel, 2011; Bye, 2008); (d) characteristics of regions within countries have not been measured or are difficult to measure (French, Sargent-Cox, Kim, \& Anstey, 2014; Monzavi, Afshari, \& Rehman, 2015); or (e) variables of interest, such as alcohol policies, are conceptualized as national (Kyskan
\& Moore, 2005; Stewart, Silcock, \& Wegman, 2012) or as differences between countries (Pomerleau et al., 2005; Rehm et al., 2009). Analyses of multiple "regions" have typically studied world regions as combinations of homogeneous countries (Lim et al., 2012; Shield et al., 2013; World Health Organization, 2014).

However, if societal patterns of drinking and its effects vary within countries, analyses that treat such patterns as homogeneous within countries may be incomplete and/or biased, and may give false impressions of drinking and its consequences in large populations. Many studies of individual countries have shown that people in different within-country regions often do not drink alike. Regional differences occur not only in drinking patterns (Bloomfield,

Correspondence: Richard W. Wilsnack, PhD, University of North Dakota School of Medicine and Health Sciences, Room E270, 1013 North Columbia Rd. Stop 9037, Grand Forks, ND 58202, USA. Phone: 701-777-3065, Email: richard.wilsnack@und.edu

Financial support: Supported by Research Grant No. R01 AA023870 from the National Institute on Alcohol Abuse and Alcoholism/ National Institutes of Health

(Multiple Principal Investigators T. Greenfield, S. Wilsnack, K. Bloomfield). The content is solely the responsibility of the authors and does not necessarily reflect the official views of NIAAA or NIH.

Declaration of interest: The authors declare that they have no competing financial or other interests

Keywords: regions, alcohol, harms, gender 
Grittner, Kraus, \& Piontek, 2017; Dwyer-Lindgren et al., 2015; Kyu, Georgiades, MacMillan, \& Boyle, 2015; Millwood et al., 2013; Shelton \& Savell, 2011), but also in antecedents and contexts of drinking (Giesbrecht et al., 2015; Roberts, 2012; Sanchez, Locatelli, Noto, \& Martins, 2013), in consequences of drinking (Jewett, Shults, Banerjee, \& Bergen, 2015; Kerr, Karriker-Jaffe, Subbaraman, \& Ye, 2011; Popova, Lange, Burd, \& Rehm, 2014; Robinson, Shipton, Walsh, Whyte, \& McCartney, 2015), and in policies intended to control drinking and the enforcement of those policies (Erickson, Lenk, Toomey, Nelson, \& Jones-Webb, 2016; Giesbrecht et al., 2013; Grönqvist \& Niknami, 2011; Kolosnitsyna, Sitdikov, \& Khorkina, 2014). Furthermore, an analysis of data from 23 countries and 132 regions, to examine country and regional variation in annual volume of alcohol consumed and in risky drinking, found that regional differences accounted for as much of the variance as country differences (Grittner et al., 2017).

National research on harmful effects of alcohol for people other than the drinker has thus far described patterns mainly in whole countries, without analyses of subareas-for example, in Australia (Laslett et al., 2010), Chile (Florenzano et al., 2015), Denmark (Seid, Grittner, Greenfield, \& Bloomfield, 2015), Finland (Huhtanen \& Tigerstedt, 2012), Laos (Jankhotkaew et al., 2017), New Zealand (Connor \& Casswell, 2012), Norway (Rossow, 2007), Thailand (Jankhotkaew et al., 2017), and the United States of America (Greenfield, Karriker-Jaffe, Kaplan, Kerr, \& Wilsnack, 2015). A few studies have looked at regional differences in harms to others within individual countries: Australia (Wilkinson \& Livingston, 2012); Canada (LewisLaietmark et al., 2017); India (Esser et al., 2016); and the United Kingdom (Gell, Ally, Buykk, Hope, \& Meier, 2015). One study (Ramstedt et al., 2015) evaluated urban versus nonurban patterns of harms experienced from heavy drinking of family and friends in six northern European countries (Denmark, Finland, Iceland, Norway, Scotland, and Sweden).

Data from European countries and from Australia found little evidence for simple urban - nonurban differences in harms to others from drinking (Ramstedt et al., 2015; Wilkinson \& Livingston, 2012), but data from five states in India showed greater harms to children in rural than in urban locations (Esser et al., 2016). Otherwise, little is known about whether within-country regional differences should be a regular part of multinational research on consequences of alcohol consumption. The purpose of this brief report is to learn whether multinational within-country regional data can improve our knowledge of differences in drinkers' selfreported drinking-related harm to persons other than the drinkers.

\section{Method}

Data for analyzing within-country variation in harm to others from drinking come from the multinational GENACIS project, now part of the larger multinational GENAHTO collaboration (Gender and Alcohol's Harm to Others; http://genahto.org/). GENACIS combined large generalpopulation surveys in 35 countries in Africa, Asia, Europe, North and South America, and Oceania. The cross-sectional surveys obtained comparable data from individuals on their patterns, problems, and contexts of alcohol consumption; social roles; intimacy and sexuality; violence and victimization; health and lifestyle; and demographic characteristics. More detailed information about the GENACIS surveys and questionnaires is summarized in Bloomfield, Gmel, and Wilsnack (2006), Graham, Bernards, Munné, and Wilsnack (2008), Obot and Room (2005), and Wilsnack et al. (2009). Individual country surveys were reviewed according to ethical principles and procedures created to protect research participants in each country. The overall GENACIS project was approved by the Institutional Review Board of the University of North Dakota.

The standardized GENACIS questionnaire asked individuals to report on up to eight ways that their drinking could have harmed other people in the past 12 months. Four questions asked respondents whether their drinking had a harmful effect on their intimate relationships, on relationships with their other family members (including children), on their friendships or social life, and on their finances. Four other questions asked individuals whether they had trouble with the law about their drinking and driving; whether a spouse or someone they lived with had left them or threatened to leave because of their drinking; whether they had lost a friendship because of their drinking; and whether they had gotten into fights while drinking.

The analyses here were limited to individuals aged 18-65 (for comparable age ranges) who consumed alcohol in the past 12 months (since 12-month abstainers would not have caused alcohol-related harms to others in that period). The data came from surveys that had asked about at least seven of the eight harms to others, and from regions (governmental subunits) in each country where at least $5 \%$ of the surveyed drinkers lived. The surveys and regions that satisfied these criteria were from Australia (2 regions), Costa Rica (4 regions), India (3 regions), New Zealand (5 regions), Nicaragua (5 regions), Nigeria (6 regions), Peru (2 regions), Spain (6 regions), Uganda (4 regions), and the United States of America (9 regions).

All the surveys analyzed had multistage random samples of the general adult population in the countries and regions surveyed. The samples were national or multi-regional within countries, with subregions surveyed in Costa Rica (urban and rural areas in and near San José) and India (subregions of Karnataka). Some surveys adjusted responses with weights (e.g., to adjust for household size in sampling), but we did not use their weights in the present analyses.

Initial analyses determined the prevalence of each of the eight alcohol-related harms reported by drinking respondents in each survey. Because the prevalence rates for each harm were generally low (see below), subsequent analyses of country and within-country regional differences examined only whether an individual reported causing one or more of the eight harms. To evaluate country and regional effects on this dichotomous outcome, we used SPSS 
multilevel modeling (Heck, Thomas, \& Tabata, 2012) for three-level models, with respondents (Level 1) nested within regions (Level 2) nested within countries (Level 3). The models were used to evaluate random effects of country and region, as well as fixed effects of variables that might account for any apparent country and regional differences in reported harms: gender, age, and the regional population prevalence of drinking. Size of variance explained by differences between countries and differences between regions is indicated by intraclass correlation coefficients (ICC).

\section{Results}

Table 1 shows the percentages of drinkers who reported causing each of the eight harms in the countries surveyed. Generally, less than $20 \%$ of drinkers in each survey reported causing each type of harm in the past year, although more than $35 \%$ of drinkers in India, Nicaragua, and Uganda reported that their drinking caused financial problems. Because of the relatively low rates of reporting most of the specific harms in most countries, and the smaller numbers of drinkers in the regions of each country, we limited further analyses to the likelihood of reporting causing one or more of the eight harms in the preceding year.

Table 1

Self-Reported Harm Prevalence in Last 12 Months by Country (Drinkers Only) (Age Range: 18-65)

\begin{tabular}{lcccccccccc}
\hline & $\begin{array}{c}\text { Intimate } \\
\text { Relation } \\
\text { ship }\end{array}$ & $\begin{array}{c}\text { Family } \\
\text { and } \\
\text { Children }\end{array}$ & $\begin{array}{c}\text { Problems } \\
\text { with } \\
\text { Friends }\end{array}$ & $\begin{array}{c}\text { Financial } \\
\text { Problems }\end{array}$ & $\begin{array}{c}\text { Trouble } \\
\text { with } \\
\text { Law }\end{array}$ & $\begin{array}{c}\text { Spouse } \\
\text { Left/ } \\
\text { Threaten } \\
\text { ed }\end{array}$ & $\begin{array}{c}\text { Lost } \\
\text { Friend }\end{array}$ & $\begin{array}{c}\text { Sot into } \\
\text { Fight }\end{array}$ & $\begin{array}{c}\text { Sample } \\
\text { Any of } 8 \\
\text { Harms }\end{array}$ & $\begin{array}{c}\text { Size } \\
\text { (All } \\
\text { Drinkers) }\end{array}$ \\
\hline Australia & $2.0 \%$ & $1.6 \%$ & $1.6 \%$ & $4.0 \%$ & $0.6 \%$ & $0.4 \%$ & $0.6 \%$ & $4.0 \%$ & $8.6 \%$ & $\mathbf{1 7 9 7}$ \\
Costa & & & & & & & & & & \\
Rica & $8.8 \%$ & $9.0 \%$ & $4.3 \%$ & $13.2 \%$ & $2.9 \%$ & $5.5 \%$ & $1.9 \%$ & $14.8 \%$ & $28.3 \%$ & $\mathbf{6 2 3}$ \\
India & $13.8 \%$ & $11.2 \%$ & $13.4 \%$ & $36.2 \%$ & $4.7 \%$ & $9.9 \%$ & $9.9 \%$ & $15.9 \%$ & $43.4 \%$ & $\mathbf{5 1 6}$ \\
New & & & & & & & & & & \\
Zealand & $12.8 \%$ & $6.8 \%$ & $6.3 \%$ & $12.7 \%$ & $0.9 \%$ & $1.1 \%$ & $1.2 \%$ & $7.5 \%$ & $24.7 \%$ & $\mathbf{1 5 9 4}$ \\
Nicaragua & $20.0 \%$ & $17.8 \%$ & $12.7 \%$ & $38.2 \%$ & $7.5 \%$ & $10.0 \%$ & $7.1 \%$ & $16.3 \%$ & $53.5 \%$ & $\mathbf{4 1 1}$ \\
Nigeria & $9.7 \%$ & $6.6 \%$ & $9.4 \%$ & $18.6 \%$ & $1.5 \%$ & $3.0 \%$ & $3.9 \%$ & $3.7 \%$ & $25.1 \%$ & $\mathbf{6 6 8}$ \\
Peru & $4.2 \%$ & $4.5 \%$ & $3.3 \%$ & $12.7 \%$ & $7.5 \%$ & $1.9 \%$ & $2.4 \%$ & $3.4 \%$ & $18.3 \%$ & $\mathbf{1 0 4 5}$ \\
Spain & $2.8 \%$ & $1.5 \%$ & $1.6 \%$ & $6.4 \%$ & $1.5 \%$ & $0.8 \%$ & $0.8 \%$ & $2.6 \%$ & $10.6 \%$ & $\mathbf{8 7 1}$ \\
Uganda & $18.2 \%$ & $17.0 \%$ & $15.1 \%$ & $43.5 \%$ & $7.0 \%$ & $9.8 \%$ & $9.3 \%$ & $12.9 \%$ & $55.7 \%$ & $\mathbf{6 8 1}$ \\
USA & $2.8 \%$ & -- & $3.7 \%$ & $2.3 \%$ & $0.6 \%$ & $0.7 \%$ & $1.2 \%$ & $2.8 \%$ & $8.1 \%$ & $\mathbf{4 1 5 0}$ \\
\hline
\end{tabular}

Table 2 shows the percentages of drinkers who reported causing at least one of the eight harms in the past year. More than $42 \%$ of the drinkers surveyed in India, Nicaragua, and Uganda reported causing at least one of the alcohol-related harms, as did roughly $25 \%$ of the drinkers in New Zealand, Nigeria, and Costa Rica, whereas harms were reported by less than $10 \%$ of the drinkers in Australia and the United States. Rates also varied greatly among the 46 regions within countries [data not shown]. In Nicaragua, for example, at least one harm was reported by $54 \%$ of women drinkers in
Bluefields, but by only $12 \%$ of women drinkers in Juigalpa. In Nigeria, $45 \%$ of male drinkers in the Plateau region but only $8 \%$ of male drinkers in the Federal Capital Territory (Abuja) reported causing at least one harm. Consistent with known gender differences in levels of alcohol consumption, a higher percentage of men than women reported causing harms in all countries except Nigeria. This gender difference occurred also in all regions (44 of 46) except for the Plateau and Rivers regions of Nigeria.

Table 2

Prevalence of One or More of Eight Harms by Country and Gender All Drinkers

Male Drinkers

\begin{tabular}{|c|c|c|c|c|c|c|c|c|c|}
\hline \multirow[b]{2}{*}{ Country } & \multicolumn{3}{|c|}{ All Drinkers } & \multicolumn{3}{|c|}{ Male Drinkers } & \multicolumn{3}{|c|}{ 然 } \\
\hline & Count & $\begin{array}{c}\% \text { of } \\
\text { Sample }\end{array}$ & $\begin{array}{l}\text { Sample } \\
\text { Size }\end{array}$ & Count & $\begin{array}{c}\% \text { of } \\
\text { Sub- } \\
\text { Sample }\end{array}$ & $\begin{array}{c}\text { Sub- } \\
\text { Sample } \\
\text { Size }\end{array}$ & Count & $\begin{array}{c}\% \text { of } \\
\text { Sub- } \\
\text { Sample }\end{array}$ & $\begin{array}{c}\text { Sub- } \\
\text { Sample } \\
\text { Size }\end{array}$ \\
\hline Australia & 154 & $8.6 \%$ & 1797 & 78 & $10.4 \%$ & 751 & 76 & $7.3 \%$ & 1046 \\
\hline Costa Rica & 176 & $28.3 \%$ & 623 & 116 & $43.1 \%$ & 269 & 60 & $16.9 \%$ & 354 \\
\hline India & 224 & $43.4 \%$ & 516 & 217 & $45.2 \%$ & 480 & 7 & $19.4 \%$ & 36 \\
\hline New Zealand & 393 & $24.7 \%$ & 1594 & 210 & $30.3 \%$ & 693 & 183 & $20.3 \%$ & 901 \\
\hline Nicaragua & 220 & $53.5 \%$ & 411 & 166 & $63.4 \%$ & 262 & 54 & $36.2 \%$ & 149 \\
\hline Nigeria & 168 & $25.1 \%$ & 668 & 114 & $24.9 \%$ & 457 & 54 & $25.6 \%$ & 211 \\
\hline Peru & 191 & $18.3 \%$ & 1045 & 135 & $31.8 \%$ & 425 & 56 & $9.0 \%$ & 620 \\
\hline Spain & 92 & $10.6 \%$ & 871 & 71 & $14.0 \%$ & 506 & 21 & $5.8 \%$ & 365 \\
\hline Uganda & 379 & $55.7 \%$ & 681 & 261 & $68.0 \%$ & 384 & 118 & $39.7 \%$ & 297 \\
\hline USA & 335 & $8.1 \%$ & 4150 & 240 & $11.3 \%$ & 2119 & 95 & $4.7 \%$ & 2031 \\
\hline
\end{tabular}


Because of the observed gender differences, gender was included as a fixed effect in the multilevel analyses of country and regional differences in reports of causing alcohol-related harms. Two other variables were included as fixed-effect variables: (1) age and (2) regional-level prevalence of drinking. Age is associated with drinking patterns (Keyes, Li, \& Hasin, 2011; White et al., 2015; Wilsnack et al., 2009) and might also be associated with reporting having caused harms to other people. We included regional-level drinking prevalence because drinkers hypothetically might be more likely to report causing harms to other people in regions where few other people drink.

Table 3

Harm Prevalence Fixed and Random Effects, Odds Ratios, and 95\% CI from 3-Level Mixed Logistic Models for 1 or More of 8 Harm Items (10 Countries/46 Regions/12,356 Individuals)

\begin{tabular}{|c|c|c|c|c|c|c|c|}
\hline \multicolumn{6}{|l|}{ Fixed Effects } & \multicolumn{2}{|c|}{ 95\% Confidence Interval } \\
\hline Model Term & Coefficient & Std. Error & $t$ & Sign. & Odds Ratio & Lower & Upper \\
\hline Intercept & .90 & .43 & 2.07 & .039 & 2.45 & 1.05 & 5.74 \\
\hline Gender $^{\mathrm{a}}$ & -.90 & .13 & -6.81 & .000 & .41 & .31 & .53 \\
\hline Age & -.03 & .01 & -3.14 & .002 & .97 & .95 & .99 \\
\hline$\%$ Drinkers/region & -.97 & .69 & -1.40 & .161 & .38 & .10 & 1.47 \\
\hline \multicolumn{8}{|l|}{ Random Effects } \\
\hline & & & & \multicolumn{4}{|c|}{ 95\% Confidence Interval } \\
\hline Random Effect Covariance & Estimate & Std. Error & $z$ & Sign. & Lower & Upper & ICC \\
\hline Country Variance (Intercept) & .65 & .35 & 1.88 & .060 & .23 & 1.85 & .16 \\
\hline Region Variance (Intercept) & .19 & .06 & 3.22 & .001 & .10 & .35 & .05 \\
\hline
\end{tabular}

${ }^{\mathrm{a}}$ Male $=1$, Female $=2$

Table 3 shows the results of testing a three-level model for drinkers' reports of causing one or more of eight harms to others because of drinking. For 10 countries and 46 regions, the table shows fixed effects of gender, age, and regional prevalence of drinking, and random effects of countries and of regions within countries. Harms caused to others were significantly less likely to be reported by women and relatively older drinkers, and more likely to be reported by men and relatively younger drinkers. The prevalence of $12-$ month drinking (versus abstention) in the regions surveyed was not significantly associated with the likelihood of reporting causing harms. Approximately $16 \%$ of the variance in self-reported harms was explained by variation between countries, as indicated by the ICC, but having only ten countries reduced the power for significance tests $(p=.06)$. Variance explained by differences between regions was somewhat smaller (ICC: 5.0\%) but remained statistically significant after taking into account country, gender, age, and the regional prevalence of drinking.

\section{Discussion}

For the fixed-effect variables, multilevel analysis confirmed the bivariate finding that female drinkers were less likely than male drinkers to report that their drinking harmed other people. This gender difference may result in part from lower levels of drinking by women, but could also reflect genderrole differences in what is considered tolerable or appropriate behavior when drinking or intoxicated (Ahlström, 1995; de Visser \& McDonnell, 2012; Iwamoto, Cheng, Lee, Takamaatsu, \& Gordon, 2011). For the total sample, younger drinkers were more likely to report that their drinking harmed others. One reason for this could be that younger drinkers have more contact with other drinkers than do older drinkers (Bond et al., 2010; Wells, Graham,
Speechley, \& Koval, 2005). The prevalence of drinking in the regions surveyed did not have a significant relationship with drinkers' reports of causing harms to others.

After taking into account gender, age, survey country, and the regional prevalence of drinking, drinkers' reports of causing alcohol-related harms to other people showed significant within-country variability across regions. Intraclass correlation coefficients suggested that selfreported harm varied more strongly across countries than across regions, but the limited number of countries (10) weakened the power for detecting statistical significance. The within-country regional variation confirmed here may be particularly important in certain countries, such as in the regions of Nicaragua and Nigeria noted above. Such regional differences have potentially important implications for alcohol policies: the formulation and enforcement of national alcohol policies may need to be modified regionally to improve prevention of harmful effects of drinking.

\section{Limitations}

Interpretations of this study's findings are limited in several important ways. The data are cross-sectional and report only what drinkers perceived as harms caused by their drinking. Causal inferences about regional effects on drinkers' harmfulness will need to be supported by future studies with longitudinal data and with measures of harms that are independent of drinkers' perceptions. A further limitation of the data is that the measure of reporting one or more of the eight harms may obscure how the specific harms are related and whether certain harms are stronger indicators than others of self-reported harmful drinking. Future sensitivity analyses and attempts at scale construction may reduce this obscurity, although the low prevalence rates of specific harms may impede such efforts. 
One other limitation of the data is that some GENACIS surveys were based on regions within countries or subdivisions within such regions, and did not sample the entire populations of their countries. The survey data thus may not provide accurate estimates of the country levels of harms. However, these survey limitations may provide a conservative test for regional effects. If harm rates were homogeneous within countries, then surveys of some but not all regions should still give accurate estimates of the country prevalence of harms, and limiting the regions studied within some countries should make it more difficult to detect regional differences that are distinct from country differences.

Several planned further analyses of data now available can improve interpretation of the results presented here. First, we hope to learn which characteristics of subnational regions may be associated with higher rates of drinker-reported harms (e.g., economic conditions, urbanization, and drinking patterns and norms other than abstention rates). Second, we hope to learn how regional patterns associated with selfreports of causing alcohol-related harm compare with regional patterns associated with self-reports of experiencing harm from others' drinking. Regional analyses of experienced harms will now be enabled by multinational data from the GENAHTO project. Third, we intend to examine possible interaction effects-for example, if associations of individual characteristics such as age and gender with self-reports of causing alcohol-related harms are contingent on regional differences in drinking patterns and drinking norms, economic conditions, and urbanization.

It is clear that the analyses here stimulate more questions than answers. However, the data here at least show that it is no longer satisfactory to conclude simply that "drinkers in country $\mathrm{X}$ report more harms caused by their drinking, compared to country Y."

\section{Acknowledgements}

The data used in this paper are from the GENAHTO Project (Gender and Alcohol's Harm to Others), supported by NIAAA Grant No. R01 AA023870 (Alcohol's Harm to Others: Multinational Cultural Contexts and Policy Implications; Multiple Principal Investigators T. Greenfield, S. Wilsnack, and K. Bloomfield). GENAHTO is a collaborative international project affiliated with the Kettil Bruun Society for Social and Epidemiological Research on Alcohol and coordinated by research partners from the Alcohol Research Group/Public Health Institute (USA), University of North Dakota (USA), Aarhus University (Denmark), the Centre for Addiction and Mental Health (Canada), the Centre for Alcohol Policy Research at La Trobe University (Australia), and the Addiction Switzerland Research Institute (Switzerland). Support for aspects of the project has come from the World Health Organization (WHO), the European Commission (Concerted Action QLG4-CT-2001-0196), the Pan American Health Organization, the Thai Health Promotion Foundation, the Australian National Health and Medical Research Council (Grant No. 1065610), and the U.S.
National Institute on Alcohol Abuse and Alcoholism/National Institutes of Health (Grants R21 AA012941, R01 AA015775, R01 AA022791, R01 AA023870, and P50 AA005595). Support for individual country surveys was provided by government agencies and other national sources.

The study directors and funding sources for data sets used in this report are: Australia: Paul Dietze, National Health and Medical Research Council (Grant 398500); Costa Rica: Julio Bejarano, World Health Organization; India: Vivek Benegal, World Health Organization; New Zealand: Jennie Connor, Otago University Research Grant; Nicaragua: José Trinidad Caldera Aburto, Pan American Health Organization; Nigeria: Akanidomo Ibanga, World Health Organization; Peru: Marina Piazza, Pan American Health Organization; Spain: Juan Carlos Valderrama, Dirección General de Atención a la Dependencia, Conselleria de Sanidad, Generalitat Valenciana; Comisionado do Plan de Galicia sobre Drogas, Conselleria de Sanidade, Xunta de Galicia; Dirección General de Drogodependencias y Servicios Sociales, Gobierno de Cantabria; Uganda: M. Nazarius Tumwesigye, World Health Organization; USA: Thomas Greenfield, U.S. National Institute on Alcohol Abuse and Alcoholism/National Institutes of Health (Grant P50 AA005595).

\section{References}

Ahlström, S. (1995). Cultural differences in women's drinking. Contemporary Drug Problems, 22(3), 393413.

Bloomfield, K., Gmel, G., \& Wilsnack, S. (2006). Introduction to special issue: Gender, culture and alcohol problems: A multi-national study. Alcohol and Alcoholism, 41, Suppl. 1, i3-i7.

Bloomfield, K., Grittner, U., Kraus, L., \& Piontek, D. (2017). Drinking patterns at the sub-national level: What do they tell us about drinking cultures in European countries? Nordic Studies on Alcohol and Drugs, 34(4), 342-352.

Bloomfield, K., Wicki, M., Wilsnack, S., Hughes, T., \& Gmel, G. (2011). International differences in alcohol use according to sexual orientation. Substance Abuse, 32(4), 210-219.

Bond, J., Roberts, S., Greenfield, T., Korcha, R., Ye, Y., \& Nayak, M. (2010). Gender differences in public and private drinking contexts: A multi-level GENACIS analysis. International Journal of Environmental Research and Public Health, 7(5), 2136-2160.

Borges, G., Ye, Y., Bond, J., Cherpitel, C. J., Cremonte, M., Moskalewicz, J., . . . Rubio-Stipec, M. (2010). The dimensionality of alcohol use disorders and alcohol consumption in a cross-national perspective. Addiction, 105(2), 240-254.

Bye, E. K. (2008). Alcohol and homicide in eastern Europe: A time series analysis of six countries. Homicide Studies, 12(1), 7-27.

Clausen, T., Rossow, I., Naidoo, N., \& Kowal, P. (2009). Diverse alcohol drinking patterns in 20 African countries. Addiction, 104(7), 1147-1154. 
Connor, J., \& Casswell, S. (2012). Alcohol-related harm to others in New Zealand: Evidence of the burden and gaps in knowledge. New Zealand Medical Journal, 125(1360), 11-27.

de Visser, R., \& McDonnell, E. (2012). "That's OK. He's a guy": A mixed-methods study of gender doublestandards for alcohol use. Psychology \& Health, 27(5), 618-639.

Dwyer-Lindgren, L., Flaxman, A. D., Ng, M., Hansen, G. M., Murray, C. J., \& Mokdad, A. H. (2015). Drinking patterns in US counties from 2002 to 2012. American Journal of Public Health, 105(6), 1120-1127.

Erickson, D. J., Lenk, K. M., Toomey, T. L., Nelson, T. F., \& Jones-Webb, R. (2016). The alcohol policy environment, enforcement and consumption in the United States. Drug and Alcohol Review, 35(1), 6-12.

Esser, M. B., Rao, G. N., Gururaj, G., Murthy, P., Jayarajan, D., Sethu, L., Jernigan, D. H., \& Benegal, V. (2016). Physical abuse, psychological abuse and neglect: Evidence of alcohol-related harm to children in five states of India. Drug and Alcohol Review, 35(5), 530 538.

Florenzano, R., Guzman, E., Sieverson, C., CastilloCarniglia, A., Fernandez, M. A., Echeverria, A., \& Barr, M. (2015). Daño a terceros producido por el alcohol: Resultados de un estudio poblacional en Chile [The harms to others from drinking: Results of a population study in Chile]. Revista Medica de Chile, 143(10), 1242-1251.

French, D. J., Sargent-Cox, K. A., Kim, S., \& Anstey, K. J. (2014). Gender differences in alcohol consumption among middle-aged and older adults in Australia, the United States and Korea. Australian and New Zealand Journal of Public Health, 38(4), 332-339.

Gell, L., Ally, A., Buykk, P., Hope, A., \& Meier, P. (2015). Alcohol's harm to others. Sheffield, United Kingdom: University of Sheffield Institute of Alcohol Studies.

Giesbrecht, N., Huguet, N., Ogden, L., Kaplan, M. S., McFarland, B. H., Caetano, R., . . Nolte, K. B. (2015). Acute alcohol use among suicide decedents in 14 US states: Impacts of off-premise and on-premise alcohol outlet density. Addiction, 110(2), 300-307.

Giesbrecht, N., Wettlaufer, A., April, N., Asbridge, M., Cukier, S., Mann, R., . . . Vallance, K. (2013). Strategies to reduce alcohol-related harms and costs in Canada: A comparison of provincial policies. Toronto, Canada: Centre for Addiction and Mental Health.

Graham, K., Bernards, S., Munné, M., \& Wilsnack, S. C. (Eds.). (2008). Unhappy hours: Alcohol and partner aggression in the Americas. Washington, DC: Pan American Health Organization.

Greenfield, T. K., Karriker-Jaffe, K., Kaplan, L. M., Kerr, W. C., \& Wilsnack, S. C. (2015). Trends in alcohol's harm to others (AHTO) and co-occurrence of familyrelated AHTO: The four US National Alcohol Surveys. Substance Abuse 9(Supplement 2), 23-51.

Grittner, U., Wilsnack, S., Kuntsche, S., Greenfield, T. K., Wilsnack, R., Kristjanson, A., \& Bloomfield, K. (2017). Regional variation in drinking behavior. Sheffield, United Kingdom: Annual Alcohol Epidemiology Symposium, Kettil Bruun Society for Social and Epidemiological Research on Alcohol.
Grönqvist, H., \& Niknami, S. (2011). Alcohol availability and crime: Lessons from liberalized weekend sales restrictions. Stockholm, Sweden: Swedish Institute for Social Research.

Heck, R. H., Thomas, S. L., \& Tabata, L. N. (2012). Multilevel modeling of categorical outcomes using IBM SPSS. New York, NY: Routledge.

Huhtanen, P., \& Tigerstedt, C. (2012). Women and young adults suffer most from other people's drinking. Drug and Alcohol Review, 31(7), 841-846.

Iwamoto, D., Cheng, A., Lee, C., Takamaatsu, S., \& Gordon, D. (2011). "Man-ing" up and getting drunk: The role of masculine norms, alcohol intoxication and alcoholrelated problems among college men. Addictive Behaviors, 36(9), 906-911.

Jankhotkaew, J., Chaiyasong, S., Waleewong, O., Siengsounthone, L., Sengngam, K., Douangvichit, D., \& Thamarangsi, T. (2017). The impact of heavy drinkers on others' health and well-being in Lao PDR and Thailand. Journal of Substance Use, 22(6), 617623.

Jewett, A., Shults, R. A., Banerjee, T., \& Bergen, G. (2015). Alcohol-impaired driving among adults-United States, 2012. Morbidity and Mortality Weekly Report, 64(30), 814-817.

Kerr, W. C., Karriker-Jaffe, K., Subbaraman, M., \& Ye, Y. (2011). Per capita alcohol consumption and ischemic heart disease mortality in a panel of US states from 1950 to 2002. Addiction, 106(2), 313-322.

Keyes, K. M., Li, G., \& Hasin, D. S. (2011). Birth cohort effects and gender differences in alcohol epidemiology: A review and synthesis. Alcoholism: Clinical and Experimental Research, 35(12), 2101-2112.

Kolosnitsyna, M., Sitdikov, M., \& Khorkina, N. (2014). Availability restrictions and alcohol consumption: A case of restricted hours of alcohol sales in Russian regions. International Journal of Alcohol and Drug Research, 3(3), 193-201.

Kyskan, C. E., \& Moore, T. E. (2005). Global perspectives on fetal alcohol syndrome: Assessing practices, policies, and campaigns in four English-speaking countries. Canadian Psychology/Psychologie Canadienne, 46(3), 153-165.

Kyu, H. H., Georgiades, K., MacMillan, H. L., \& Boyle, M. H. (2015). Community- and individual-level factors associated with smoking and heavy drinking among Aboriginal people in Canada. Canadian Journal of Public Health, 106(2), e22-e28.

Laslett, A.-M., Catalano, P., Chikritzhs, T., Dale, C., Doran, C., Ferris, J., . . . Room, R. (2010). The range and magnitude of alcohol's harm to others. Deakin West, Australian Capital Territory: Alcohol Education and Rehabilitation Foundation.

Lewis-Laietmark, C., Wettlaufer, A., Shield, K. D., Giesbrecht, N., April, N., Asbridge, M, . . Stockwell, T. (2017). The effects of alcohol-related harms to others on self-perceived mental well-being in a Canadian sample. International Journal of Public Health, 62(6), 669-678.

Lim, S. S., Vos, T., Flaxman, A. D., Danaei, G., Shibuya, K., Adair-Rohani, H., ... Aryee, M. (2012). A comparative risk assessment of burden of disease and injury 
attributable to 67 risk factors and risk factor clusters in 21 regions, 1990-2010: A systematic analysis for the Global Burden of Disease Study 2010. The Lancet, 380(9859), 2224-2260.

Millwood, I. Y., Li, L., Smith, M., Guo, Y., Yang, L., Bian, Z., . . . Chen, J. (2013). Alcohol consumption in 0.5 million people from 10 diverse regions of China: Prevalence, patterns and socio-demographic and health-related correlates. International Journal of Epidemiology, 42(3), 816-827.

Monzavi, S.M., Afshari, R., \& Rehman, N. (2015). Alcohol related disorders in Asia Pacific region: Prevalence, health consequences and impacts on the nations. Asia Pacific Journal of Medical Toxicology, 4(1), 1-8.

Obot, I. S., \& Room, R. (Eds.). (2005). Alcohol, gender and drinking problems: Perspectives from low and middle income countries. Geneva, Switzerland: World Health Organization.

Pomerleau, J., McKee, M., Rose, R., Haerpfer, C. W., Rotman, D., \& Tumanov, S. (2005). Drinking in the Commonwealth of Independent States - evidence from eight countries. Addiction, 100(11), 1647-1668.

Popova, S., Lange, S., Burd, L., \& Rehm, J. (2014). Canadian children and youth in care: The cost of fetal alcohol spectrum disorder. Child \& Youth Care Forum, 43(1), 83-96.

Ramstedt, M., Sundin, E., Moan, I. S., Storvoll, E. E., Lund, I. O., Bloomfield, K., . . . Tigerstedt, C. (2015). Harm experienced from heavy drinking of family and friends in the general population: A comparative study of six Northern European countries. Substance Abuse: Research and Treatment, 9(Supplement 2), 107-118.

Rehm, J., Mathers, C., Popova, S., Thavorncharoensap, M., Teerawattananon, Y., \& Patra, J. (2009). Global burden of disease and injury and economic cost attributable to alcohol use and alcohol-use disorders. The Lancet, 373(9682), 2223-2233.

Roberts, S. C. M. (2012). Macro-level gender equality and alcohol consumption: A multi-level analysis across U.S. states. Social Science \& Medicine, 75(1), 60-68.

Robinson, M., Shipton, D., Walsh, D., Whyte, B., \& McCartney, G. (2015). Regional alcohol consumption and alcohol-related mortality in Great Britain: Novel insights using retail sales data. BMC Public Health, 15, 1.

Rossow, I. (2007). Trends in alcohol consumption and alcohol-related harms in Norway around the turn of the millennium. Nordic Studies on Alcohol and Drugs, 24(Suppl.), 61-72.

Sanchez, Z. M., Locatelli, D. P., Noto, A. R., \& Martins, S. S. (2013). Binge drinking among Brazilian students: A gradient of association with socioeconomic status in five geo-economic regions. Drug and Alcohol Dependence, 127(1), 87-93.

Seid, A. K., Grittner, U., Greenfield, T. K., \& Bloomfield, K. (2015). To cause harm and to be harmed by others: New perspectives on alcohol's harms to others. Substance Abuse: Research and Treatment, 9(Supplement 2), 13-22.

Shelton, N., \& Savell, E. (2011). The geography of binge drinking: The role of alcohol-related knowledge, behaviours and attitudes: Results from the Health
Survey for England 2007. Health \& Place, 17(3), 784792.

Shield, K. D., Rylett, M., Gmel, G., Gmel, G., Kehoe-Chan, T. A. K., \& Rehm, J. (2013). Global alcohol exposure estimates by country, territory and region for 2005 A contribution to the Comparative Risk Assessment for the 2010 Global Burden of Disease Study. Addiction, 108(5), 912-922.

Stewart, K., Silcock, D., \& Wegman, F. (2012). Reducing drink driving in low- and middle-income countries: Challenges and opportunities. Traffic Injury Prevention, 13(2), 93-95.

Wells, S., Graham, K., Speechley, M., \& Koval, J. J. (2005). Drinking patterns, drinking contexts and alcoholrelated aggression among late adolescent and young adult drinkers. Addiction, 100(7), 933-944.

White, A., Castle, I. J., Chen, C. M., Shirley, M., Roach, D., \& Hingson, R. (2015). Converging patterns of alcohol use and related outcomes among females and males in the United States, 2002 to 2012. Alcoholism: Clinical and Experimental Research, 39(9), 1712-1726.

Wilkinson, C., \& Livingston, M. (2012). Distances to onand off-premise alcohol outlets and experiences with alcohol-related amenity problems. Drug and Alcohol Review, 31(4), 394-401.

Wilsnack, R. W., Wilsnack, S. C., Kristjanson, A. F., Vogeltanz-Holm, N. D., \& Gmel, G. (2009). Gender and alcohol consumption: Patterns from the multinational GENACIS project. Addiction, 104(9), 1487-1500.

World Health Organization. (2014). Global status report on alcohol and health. Geneva, Switzerland: World Health Organization. 